\title{
MODELLING METHODOLOGY OF PISTON PNEUMATIC AIR ENGINE OPERATION
}

\author{
Dariusz SZPICA, ${ }^{*}$ Michal KORBUT*
}

*Faculty of Mechanical Engineering, Bialystok University of Technology, ul. Wiejska 45c, 15-351 Białystok, Poland

d.szpica@pb.edu.pl, korbutmichal@gmail.com

received 16 December 2019, revised 16 January 2020, accepted 18 January 2020

\begin{abstract}
The article presents a mathematical model describing the operation of a piston pneumatic air engine. Compressed air engines are an alternative to classic combustion solutions as they do not directly emit toxic exhaust components. In the study, a modified internal combustion piston engine was adopted as pneumatic engine. The mathematical model was divided on the two subsystems, that is, mechanical and pneumatic. The mechanical subsystem describes a transformation of compressed air supply process parameters to energy transferred to the piston and further the conversion of the translational to rotary motion; in turn, in the pneumatic part, the lumped elements method was used. Calculations were carried out using the Matlab-Simulink software, resulting in the characteristics of external and economic indicators. The presented mathematical model can be ultimately developed with additional elements, such as the intake or exhaust system, as well as timing system control.
\end{abstract}

Key words: Mechanical engineering, drive sources, pneumatic engine, modelling

\section{INTRODUCTION}

In the subsequent years, the emission limits of the exhaust toxic components for the transport sector are successively reduced. The proposed WLTP (http://wltpfacts.eu/) and RDE (Commission Regulation 2017/1154, 2017) driving tests necessitating the vehicles' producers to finding the new emission reduction methods. There are still non-road vehicles (Wargula et al., 2018) in case of which steps are taken to reduce their emission (Walus et al., 2018). In general, the European Union regulations indicate on the reduction of $G H G$ by ca. $20 \%$ by 2030 compared to the emissions in 2008 (A policy framework for climate and energy..., 2014).

Many possible solutions of reducing the exhaust toxic components in the powertrains of transport means can be distinguished:

a) The organisation of processes related to the operation

of internal combustion engine:

- ATAC (Onishi et al., 1979),

- CAI / HCCI (Jeuland et al., 2004),

- HPDI or RCCI (Mikulski et al., 2018),

- usage of exhaust purification systems (Fox et al., 2019; Senthil Kumar et al., 2019; Resitoglu et al., 2020),

- design changes,

- more efficient control algorithms.

b) Use of alternative energy sources:

- for example, LPG or CNG (Raslavicius et al., 2014; Borawski, 2015; Pulawski and Szpica, 2015), biogas (Mikulski et al., 2015) and others,

- electric drive (Grigor'ev et al., 2015),

- hydraulic/pneumatic drive (Simon, 2017),

- hybrid systems (Brejaud et al., 2011; Dimitrova and Marechal, 2015; Raslavicius et al., 2017).
Pneumatics drives used in road transport are not popular. Only MDi company (https://www.mdi.lu/) attempted to introduce a series of cars using the pneumatic engines in the powertrain system. The Engineair Company (http://www.engineair.com.au/) is conducting advanced researches on the efficiency improvements of the pneumatic engines. Pneumatic engines have many possible variants, that is, reciprocating, rotary, unconventional, for example, Di Pietro (Zwierzchowski, 2017). In many cases presented in the literature, the pneumatic engine is a modification of a two or a four stroke internal combustion engine (Mitianiec, 2008; Allam and Zakaria, 2018). The researches also concern vane (Badr et al., 1985; Librovich and Nowakowski, 2004) and rotary (Dvorak et al., 2017) engines.

Many studies can be found in the literature regarding the operation of the piston pneumatic engine (i.e., Michael et al. (2012), Kalekin et al. (2014), or Semenchukova et al. (2018), Fang et al. (2018)). In the mechanical part, the mathematical models are based on the description of a piston machine. The pneumatic part describes the air flow through the inlet and outlet valves and a variable volume chamber representing the cylinder. Dvorak et al. (2017) used a standard subsystems blocks from the Matlab environment in the course of the mathematical modelling, demonstrating the compatibility of model and experimental courses for the transition states of the rotary engines.

The modelling methods described above were based on the values averaged over a working cycle. It has become significant to indicate the variability of these values within one cycle, constituting the basis for further simulation or strength calculations of working elements. The study proposes a methodology for modelling an operation of the pneumatic piston engine combining two subsystems, mechanical and pneumatic. In the pneumatic part, it was proposed that the lumped element method be used (Kaminski, 2013, Kaminski 2014, Szpica, 2018b). 


\section{THE RESEARCH OBJECT}

The object of the research was conceptual piston pneumatic air engines with the parameters presented in Table 1. The engine (Fig. 1a) was based on a JAWA 50 (http://www.jawa-50.cz) combustion engine, which was a 2-stroke unit with a gas exchange operated by the piston motion. The scope of the engine modification for compressed air supply included:

- the intake system in which the carburettor was removed and the intake channel was plugged (1 in Fig. 1b),

- in the spark plug place, the solenoid valve enabling cyclically air supply was mounted ( 2 in Fig. 1b),

- a custom plate was used between the cylinder head and the cylinder to lower the compression ratio (3 in Fig. 1c),

- a custom plate was mounted between the engine block and the cylinder for blocking the scavenging system operation (4 in Fig. 1c),

a)

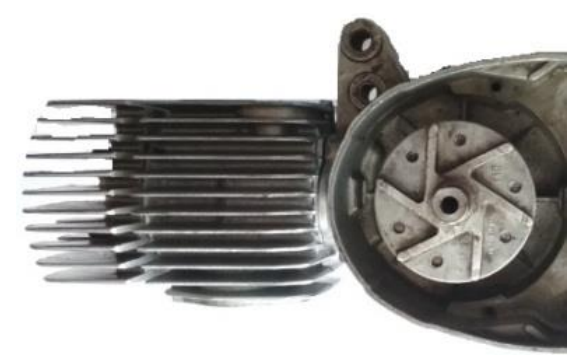

b)

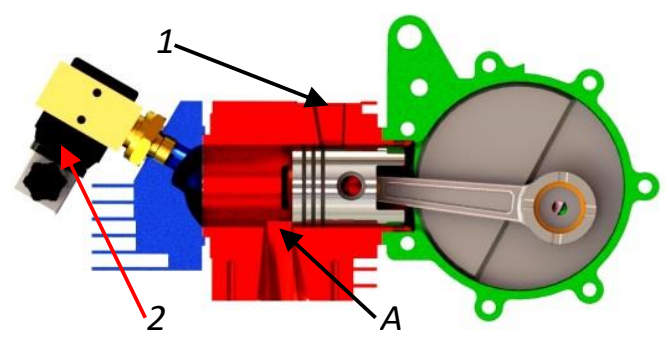

c)

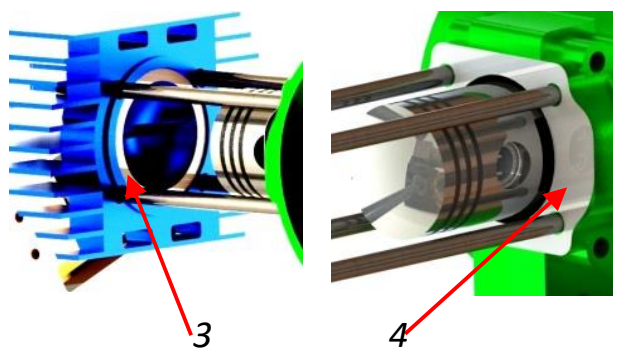

Fig. 1. Subject of the modelling: a - real view, $\mathrm{b}-C A D$ model, $c$ - modifications (description in the main text)

The use of a custom plate 3 (Fig. $1 \mathrm{~b}$ ) was necessary as the engine with a base compression ratio of 9:1 could generate about $10 \mathrm{e}^{5} \mathrm{~Pa}$ at the end of the compression stroke. Initially, assuming a compressed air supply pressure value at $10 \mathrm{e}^{5} \mathrm{~Pa}$, it would be tough to expect measurable engine energy effects. Hence, the decision to reduce the compression ratio. The custom plate 4 and plate 1 was used to block the operation of the crankcase as the pump pumping over the piston.
The modified engine works as a two-stroke engine, with the processes occurring only over the piston, without the crankcase involvement. As a result of the crankshaft rotation, the piston closes the outlet window ( $A$ in Fig. $1 b)$ and the compression process starts. Close to the TDC, intake of the compressed air starts realized by solenoid valve 2. Compressed air is responsible for producing pressure force on the piston to create a crankshaft torque in a work stroke. The pressure generated in the crankcase is neutralised by the gearbox, which is originally locked to the engine. The holes between the engine crankcase and the gearbox, in addition to the neutralisation, provide the lubrication of the crankshaft bearings.

Tab. 1. The two stroke piston pneumatic air engine technical data

\begin{tabular}{|c|c|c|}
\hline parameter & unit & value \\
\hline number of cylinders & - & 1 \\
\hline $\begin{array}{r}\text { timing system (max. throughput): inlet } \\
\text { outlet }\end{array}$ & $\begin{array}{l}m^{2} \\
m^{2}\end{array}$ & $\begin{array}{r}12.723 e-6 \\
238.400 e-6\end{array}$ \\
\hline displacement / volume & $\mathrm{m}^{3}$ & $0.5479 \mathrm{e}-6$ \\
\hline bore & $\mathrm{m}$ & $40.000 \mathrm{e}-3$ \\
\hline stroke & $\mathrm{m}$ & $43.600 \mathrm{e}-3$ \\
\hline connecting rod length & $\mathrm{m}$ & $100.000 \mathrm{e}-3$ \\
\hline compression ratio & - & $4: 1$ \\
\hline $\begin{array}{l}\text { weight of the components involved in } \\
\text { the reciprocal motion }\end{array}$ & $\mathrm{kg}$ & 0.142 \\
\hline $\begin{array}{l}\text { substitute mass of the part of the con- } \\
\text { necting rod rotating on radius } R \text { of the } \\
x \text {-th crank }\end{array}$ & $\mathrm{kg}$ & 0.140 \\
\hline
\end{tabular}

\section{SIMULATION METHODOLOGY}

The scheme presented in Fig. 2 was used for the model description.

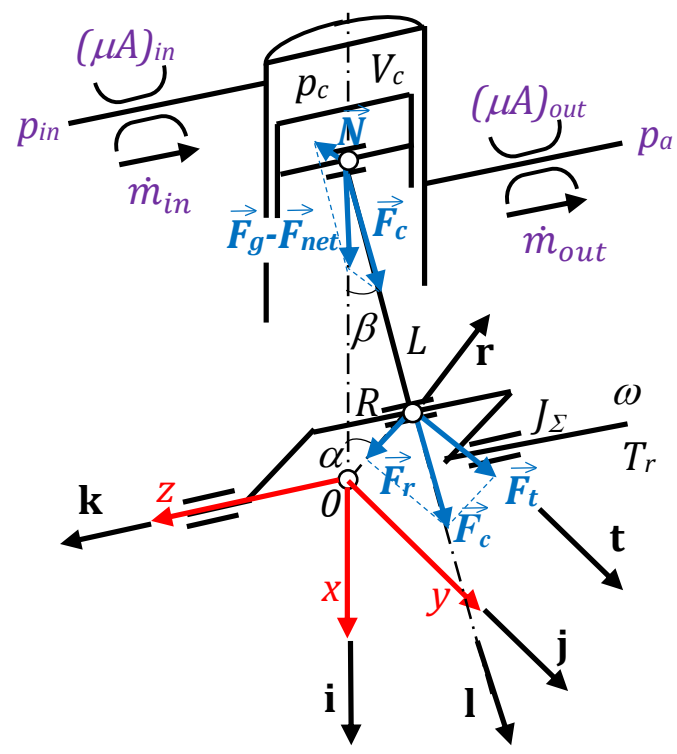

Fig. 2. Scheme of the mechanical and pneumatic subsystem (description in the main text)

The relevant assumptions for building the mathematical representation of both subsystems were as follows: 
a) mechanical subsystem:

- the torque transfer system was perfectly stiff,

- the influence of elastic vibrations was omitted,

- energy flow flowed without loss,

- the pressure course depended on the timing and input and output pressure as well as the position of the piston,

- the moment of inertia of the crankshaft and flywheel were omitted at angular velocity analysis.

b) pneumatic subsystem:

- the air was regarded as a thermodynamically ideal gas, while being viscous and compressible,

- the flow took place without internal friction and heat exchange with the surroundings,

- the state of the air was constant in a given volume and depended on time,

- the joints of the individual elements of the tested object were perfectly airtight,

- the air properties were assumed to be uniform both in the local volume and in the entire cross-section of the flow through the local resistance,

- the air temperature was constant in the process.

In the model description, two presented subsystems were combined, where as a result of the compressed air supply (replacement of the combustion, as it was in the original design), force was generated on the piston that created torque and engine speed. The engine load conditions determined filling and emptying of the cylinder.

In the description of the mechanical part, based on the scheme presented in Fig. 2 and Appendix, the general equation of the process in mechanical subsystem was:

$\left[\begin{array}{c}\omega \\ T_{r}\end{array}\right]=$

$\left[\begin{array}{cc}0 ; & \left(R A_{p}\left(\sin \alpha+\frac{\lambda}{2} \sin 2 \alpha\right)\right)^{-1} \\ \frac{R A_{p} \sin (\alpha+\beta)}{\cos \beta} ; & -\frac{R m_{A}}{A_{p}} \frac{\sin (\alpha+\beta)}{\cos \beta}\end{array}\right]\left[\begin{array}{l}p_{c}(\alpha) \\ \dot{V}_{c}(\alpha)\end{array}\right]$

In two stroke, one-cylinder engines that work cycle of which involves one full crankshaft revolution, the $S(\alpha)$ function for the one-cylinder engine was:

$S(\alpha)=\frac{\sin (\alpha+\beta)}{\cos \beta}=\frac{\lambda \sin 2 \alpha}{2-\lambda^{2} \sin ^{2} \alpha}+\sin \alpha$

The equation of engine torque was presented in the form:

$T_{r}=R A_{p} S(\alpha) p_{c}(\alpha)-R^{2} m_{A} S(\alpha)(\cos \alpha+\lambda \cos 2 \alpha) \omega^{2}$

The engine torque calculated from Eq. 3 is the indicated engine torque. To obtain effective power, the mechanical efficiency of the system should be taken into consideration.

The description omits the influence of many factors, that is, friction, the coefficient of which can be determined using the methods presented in (Borawski, 2016; Borawski, 2019).

When the instantaneous torque is greater than the average one, the instantaneous speed increases, when is smaller - decreases. This is the result of the fact that mechanical work of the engine is equal with the increase in the kinetic energy accumulated in the rotating masses of the engine components. When we compared the work and the energy, we could calculate the instantaneous angular crankshaft speed: $\omega_{i}= \begin{cases}\sqrt{\omega_{i-1}^{2}-\frac{2 T_{r} \Delta \alpha}{J_{E}^{\sum}}}, T_{r} \leq T_{\text {mean }} \\ \sqrt{\omega_{i-1}^{2}+\frac{2 T_{r} \Delta \alpha}{J_{E}^{\sum}}}, T_{r}>T_{\text {mean }}\end{cases}$

The mass moment of inertia of the rotating elements of the engine was:

$J_{E}^{\sum}=0.64 m_{B} R^{2}$

The main problem in the modelling processes was the determination of mean torque value $T_{\text {mean }}$ in cycle, which depended directly on the supplying conditions and angular crankshaft speed $\omega$. It was necessary to change the $T_{\text {mean }}$ value in subsequent approximations, to get closer to the $\omega$ reference value.

Pressure in cylinder (Fig. 2 and Appendix) was described:

$\frac{\mathrm{d} p_{c}}{\mathrm{~d} t}=\frac{\kappa R_{g} T_{g}}{V_{c}}\left(\dot{m}_{\text {in }}-\dot{m}_{\text {out }}-\frac{p_{c}}{R_{g} T_{g}} \frac{\mathrm{d} V_{c}}{\mathrm{~d} t}\right)$

where:

$\dot{m}_{\text {in }}=(\mu A)_{\text {in }} \frac{p_{\text {in }}}{\sqrt{R_{g} T_{g}}} \psi_{\max } b \frac{p_{\text {in }}-p_{c}}{b p_{\text {in }}-p_{c}}$

and

$\dot{m}_{\text {out }}=(\mu A)_{\text {out }} \frac{p_{c}}{\sqrt{R_{g} T_{g}}} \psi_{\max } b \frac{p_{c}-p_{a}}{b p_{c}-p_{a}}$

because $p_{\text {out }}=p_{a}$.

\section{NECESSARY PARAMETER TO INITIATE CALCULATION}

To initiate the calculation, it was necessary to specify the input parameters that should be distinguished:

- inlet pressure: $p_{\text {in }}=10 \mathrm{e}^{5} \mathrm{~Pa}$,

- atmospheric pressure: $p_{a}=1 \mathrm{e}^{5} \mathrm{~Pa}$,

- air temperature: $T_{g}=293.15 \mathrm{~K}$,

- adiabatic exponent: $\kappa=1.4$,

- gas constant: $R_{g}=287.15 \mathrm{~J} /(\mathrm{kg} \mathrm{K})$,

- max. value of the $S V W$ function: $\psi_{\max }(\sigma)=0.578$,

- factor of the $M A$ function: $b=1.13$,

- throughput of the timing system: see Fig. 3 and Fig. 4.

The Inlet side flow characteristics were determined on the basis of the solenoid valves dynamical characteristics analysis, in this case $L P G$ vapour phase pulse injector (Duk and Czarnigowski, 2012; Czarnigowski, 2012; Szpica, 2016). Initially, for the compressed air supply, the solenoid valve $2 \mathrm{M}-15 \frac{1}{2}{ }^{\prime \prime} 0-16$ bar $24 \mathrm{~V}$ with flow diameter $d_{v}=4.5 \mathrm{~mm}$ was provided. In this type of final control elements, specified inlet time $t_{\text {inlet }}$ (Fig. 3 throughput absolute values) consisted of: opening time $t_{o}$, time of full opening $t_{f o}$ and closing time $f_{c}$. It follows that the inlet time must contain imperfections in the opening and closing process. The solenoid valve opening and closing process analysis allowed on describing the inlet process in three time dependent ranges:

$\frac{(\mu A)}{(\mu A)_{\max }}(t)=\left\{\begin{aligned} \frac{1}{t_{o}^{2}} t^{2}, & \leq t<t_{o} \\ 1, & t_{o} \leq t<t_{o}+t_{f o} \\ -\frac{1}{t_{c}^{2}} t^{2}+1, t_{o} & +t_{f o}<t \leq t_{\text {inlet }}\end{aligned}\right.$

In the case of the solenoid valve supply, IVO can be implemented in any way in regard of the $T D C$. To increase the supply efficiency, the solenoid valve with piezoelectric actuator can be 
used (Mieczkowski, 2017; Mieczkowski, 2018; Mieczkowski, 2019, Mieczkowski et al, 2020), which significantly reduce the opening and closing time if used in a double version.

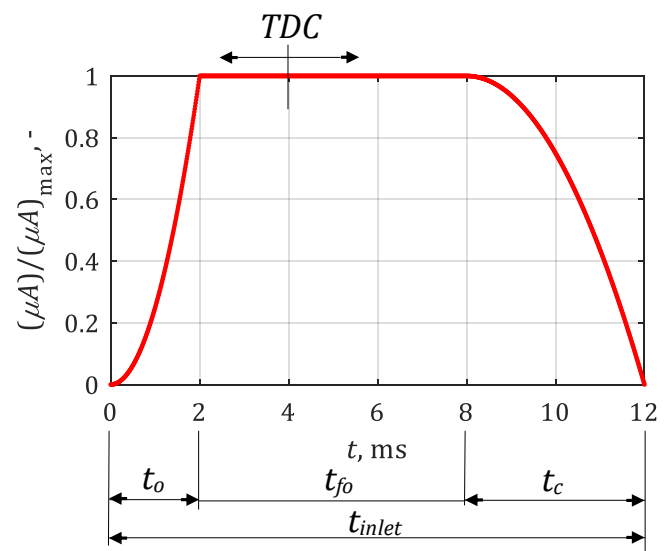

Fig. 3. Example course of the inlet process as a time function: $t_{o}=2 \mathrm{~ms}, t_{c}=4 \mathrm{~ms}, t_{\text {fo }}=3 \mathrm{~ms}, t_{\text {inlet }}=12 \mathrm{~ms}$

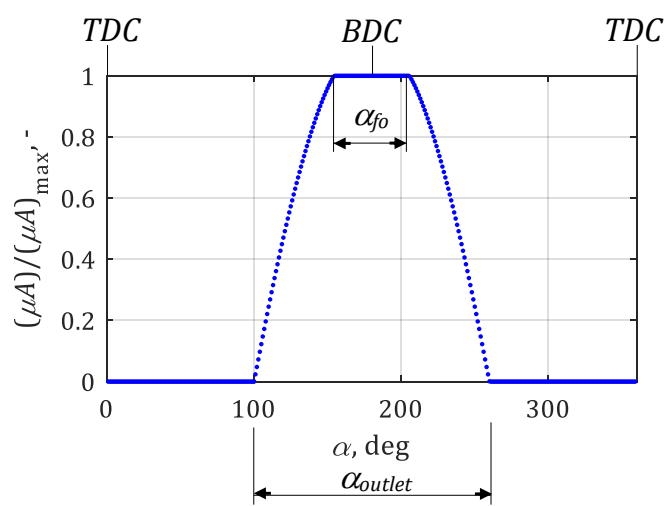

Fig. 4. Course of the outlet process as a crankshaft rotation angle function

To determine the course of the cylinder outlet port opening was used engine $C A D$ model. After developing the outlet port surface, the change of the flow area cross section in a function of a crankshaft rotation angle was determined in absolute values of throughput, which is presented in Fig. 4. In this case, the opening is symmetrical relative to the $B D C$. The value of $t_{f o}$ depended on the position of the bottom edge of the port relative to the $B D C$.

Boundary conditions of simulation for $t=0 \mathrm{~s}$ was established as:

- angle of crankshaft rotation: $\alpha=0 \mathrm{rad}$,

- displacement of pistons: $x=0 \mathrm{~mm}$,

- volume of cylinder: combustion chamber $V_{c}=V_{\min }$,

- pressure in cylinder: depending on load conditions and rotational speed,

- timing system: $(\mu A)_{\text {in }}$ - depending on the adopted variant of analysis, $(\mu A)_{\text {out }}=0 \mathrm{~m}^{2}$ (Fig. 4),

- number of cycles analysing for determining the mean -10 .

\section{RESULTS OF THE SIMULATION}

The simulations were carried out using the Matlab-Simulink environment. The differential (Eq. 6) was solved numerically with the implicit trapezoidal method combined with reverse differentiation (ode23tb, variable-step, max step size 0.0001, min step size auto). Solution Eq. 6 is obtained as a function of time $t$; so, before starting the simulation, the angle increment $\alpha$ was calculated with a determined value $\omega$. Knowing the angle increment $\alpha$ allowed the camshaft phases $(\mu A)=f(\alpha)$ to be loaded into the working space. To calculate $T_{r}$ (Eq. 3), a value of $\alpha=f(t)$ and $p_{c}=f(\alpha)$ was required, which was obtained from (Eq. 6). With $T_{r}=f(\alpha)$ and $T_{\text {mean }}$, it was possible to calculate $\omega=f(\alpha)$ with Eq. 4.

At the beginning of the calculation, it is important to specify the initial pressure at the simulation start. It affects the shape of the indicator diagram. Examples of the indicator diagrams with different value of initial pressure in cylinder were shown in Fig. 5. The simulation initial pressure value should be corrected each time for load conditions and rotational speed. a)

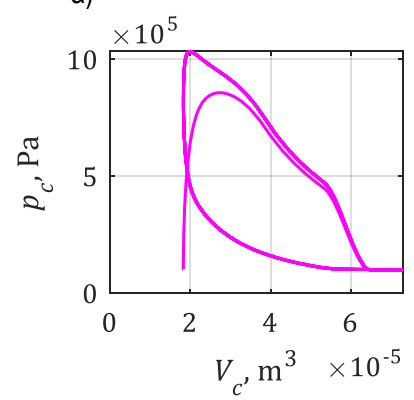

b)

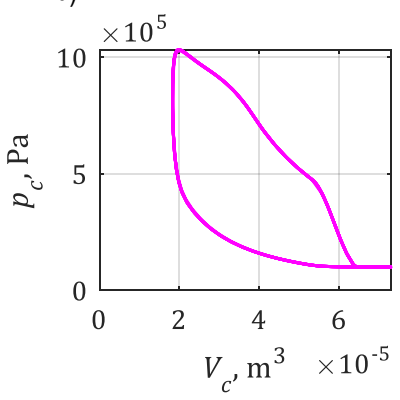

Fig. 5. Examples of the indicator diagrams: a - low pressure at the start of the simulation $(1 \mathrm{e} 5 \mathrm{~Pa}), \mathrm{b}$ - proper value of the pressure at the start of the simulation $(8 \mathrm{e} 5 \mathrm{~Pa})$

In the next step, the determined mean load torque value $T_{\text {mean }}$ should be approximated due to the fact that it has direct influence on the achieved angular speed. Therefore, the simulation is performed several times, for questing a compliance between the specified $T_{\text {mean }}$ torque and the resulting mean torque from a certain number of cycles (crankshaft rotations). On its basis, the power could be calculated:

$P=T_{\text {mean }} \omega=T_{\text {mean }} 2 \pi n$

where: $n=\omega / 2 \pi$.

and

$B S A C=\dot{m}_{i n} / P$

For simulation initialization, into the program workspace should be loaded the courses of the inlet and outlet process as a function of crankshaft rotation (Fig. 6).

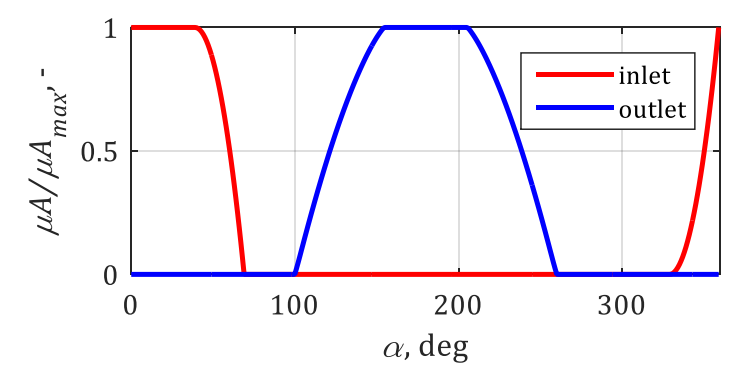

Fig. 6. Example courses of the inlet and outlet process as a crankshaft rotation $(n=2000 \mathrm{rpm})$ 
As a result of the calculations carried out, the courses of the inlet and outlet process $\mu A / \mu A_{\max }$, pressure in cylinder $p_{c}$, torque $T_{r}$ and rotation speed $n$ as a time function were received (Fig. 7). The results are presented as a function of time $t$ with regard to the specificity of solving Eq. 6 , where pressure $\mathrm{d} p_{c} / \mathrm{d} t$ is the determining factor for $T_{r}$ and $\mathrm{n}$. Fig. 7 presents the last 5 cycles out of the 10 performed due to the fact that there is a possibility of interference in the first cycles with inadequate selection of pressure $p_{c \text { start }}$ and $T_{\text {mean }}$. Significant rotational speed fluctuations can be observed resulting from IVO, and the assumption of only the mass $m_{B}$ was the rotational inertia load (Eq. 5), without taking into account the crankshaft and flywheel mass moment of inertia.

The results presented in Fig. 7 were obtained with IVO = $30 \mathrm{deg} B T D C$, inlet time $t_{\text {inlet }}$ equal to the $100 \mathrm{deg}$ of a crankshaft rotate (control disc on a crankshaft with impulse transmitter for opening and closing), opening and closing time $t_{o}=$ $t_{c}=2.5 \mathrm{~ms}$. For adopted values and input courses, the values of mean torque $T_{\text {mean }}=4.46 \mathrm{Nm}$, rotational speed $n=$ $880 \mathrm{rpm}$, power $P=0.41 \mathrm{~kW}$ and the stream of supplying air $\dot{m}=0.053 \mathrm{~kg} / \mathrm{s}$ were obtained. Due to that, $B S A C=$ $46.38 \mathrm{~kg} /(\mathrm{kWh})$.
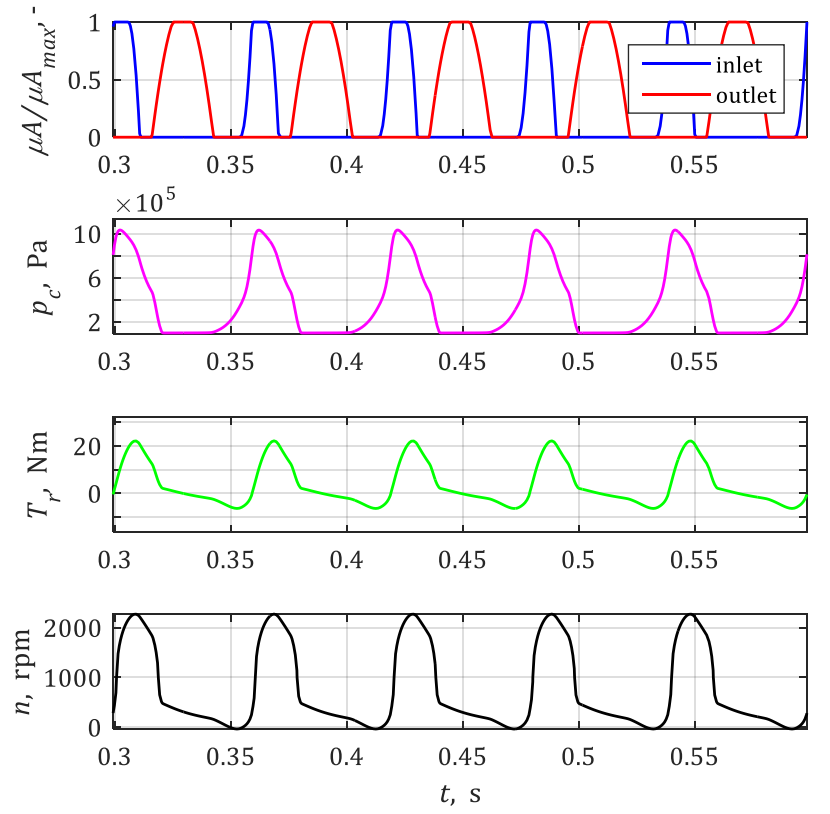

Fig. 7. Example calculation results

Using created calculation algorithm, the engine full load characteristics and performance were determined (Fig. 8) in relation to the energy and the economic indicators based on the indicated values. The shape of the characteristics is similar to the shape of the characteristics of internal combustion engines. The main difference consists of the rotational speed range, especially the lower value of speed in which the pneumatic engine is able to operate in situated below combustion engine possibility. The points of occurrence of the maximum torque $T_{r \max }$ and the minimum BSAC occur on opposite sides of the characteristic, as in a combustion engine (Heywood, 1988). From around $2000 \mathrm{rpm}$ is revealing a decrease in the mass stream of air supplying the engine $\mathrm{d} m / \mathrm{d} t=\dot{m}$. The assumed range of inlet valve opening angle seems to be correct, however, the operation of it is deter- mined by the opening time $t_{o}$ and closing time $t_{c}$, which at higher speeds often do not allow to achieve full opening.

In order to compare a pneumatic engine and its basing combustion engine, it is necessary to take into account the mechanical efficiency, for which the values for internal combustion piston engines are in the range $\eta_{m}=0.80 \ldots 0.92$ (Heywood, 1988) and can be taken as reference value for pneumatic engines. In the calculations, it was assumed $\eta_{m}=0.85$. Statement of the energetic indicators is presented in Table 2 . The maximum computational power of the pneumatic engine is $50 \%$ lower than the basic combustion variant. In turn, the maximum torque is $30 \%$ higher. In the case of torque, the decisive factor is the rotation speed, which is nearly 3 times lower than in the combustion equivalent. The pneumatic engine from $4000 \mathrm{rpm}$ is characterized by a significant decrease in energy indicators.
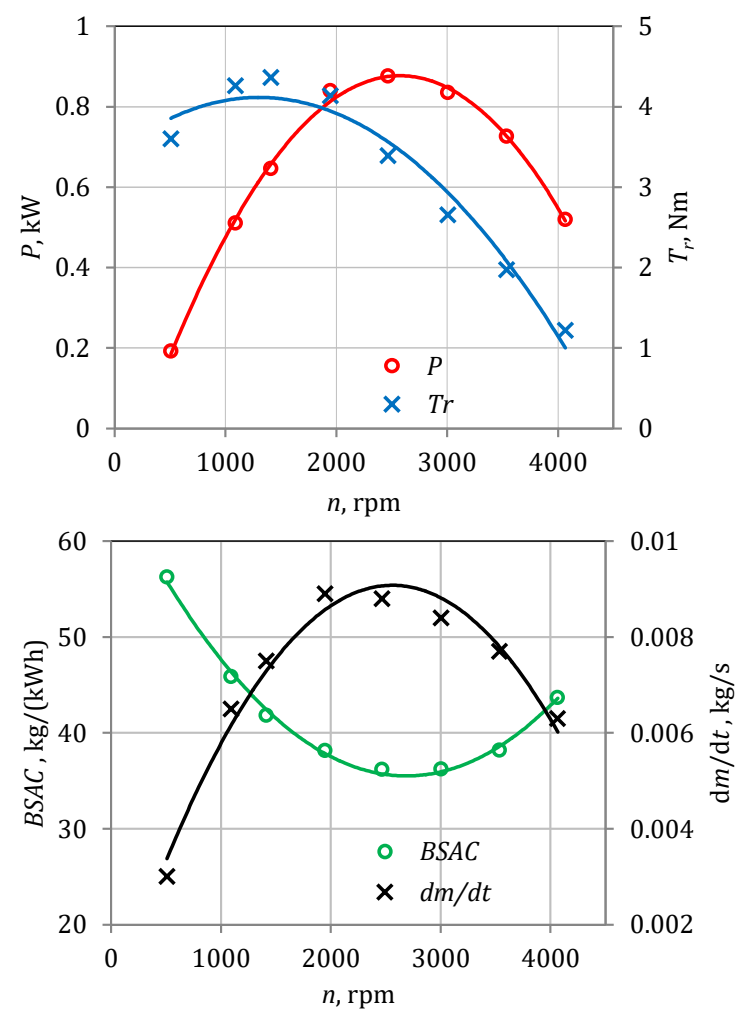

Fig. 8. Full load pneumatic engine speed characteristics

Tab. 2. The combustion and pneumatic engine comparison

\begin{tabular}{|l|c|c|}
\hline \multicolumn{1}{|c|}{ parameter } & combustion & pneumatic \\
\hline maximum power & $1.49 \mathrm{~kW}$ & $0.78 \mathrm{~kW}$ \\
\hline rotation speed of the maximum power & $6500 \mathrm{rpm}$ & $2467 \mathrm{rpm}$ \\
\hline maximum torque & $2.85 \mathrm{Nm}$ & $3.71 \mathrm{Nm}$ \\
\hline rotation speed of the maximum torque & $4500 \mathrm{rpm}$ & $1413 \mathrm{rpm}$ \\
\hline
\end{tabular}

The mathematical model presented in the study was used to determine the engine full load characteristics and performance. It is possible to use it in regulatory characteristics such as the impact of $I V O, t_{\text {inlet }}$ or $p_{\text {in }}$ on $T_{r}$ or $B S A C$. At present, a prototype of the piston pneumatic engine proposed in the study was built. Work is underway to verify the mathematical model in relation to the real object, what will be the subject of subsequent publications. 


\section{CONCLUSIONS}

The study presents a mathematical model of a piston pneumatic air engines. As a research object, a two-stroke JAWA 50 combustion engine was selected, which has been subjected to the necessary modifications to enable compressed air supply. In the scope of the simplifications adopted, engine modelling was divided into two sub-subsystems: mechanical, which described the transformation of compressed air energy into reciprocating machine torque, and pneumatic, where lumped elements method was used. The connecting part of both subsystems was the engine cylinder, which on the one hand determined the generated torque and speed, however, its filling and emptying was a result of the timing system. Carried out calculations allowed the assessment of the engine parameters within one working cycle. Significant torque and speed fluctuations have been indicated as a result of the low filling frequency and operation setting of the inlet valve operation. As a result, the engine full load characteristics and performance were determined. The maximum computational power of a pneumatic engines is $50 \%$ lower than the basic combustion variant. In turn, the maximum torque is $30 \%$ higher. In the case of torque, the decisive factor is the rotation speed, which is nearly 3 times lower than in the combustion equivalent. The pneumatic engines from $4000 \mathrm{rpm}$ is characterized by a significant decrease in energy indicators. The structure of the presented mathematical model and calculation methodology allow to use it in the initial assessment of the impact of selected input parameters of the pneumatic and mechanical system on both, the energy and the economic external indicators.

Nomenclature: ATAC - Active Thermo-Atmosphere Combustion, BDC - Bottom Dead Centre, BTDC - Before TDC, BSAC Brake-Specific Air Consumption, CAD - Computer Aided Design, CAI - Controlled Auto-Ignition, CNG - Compressed Natural Gas, GHG - GreenHouse Gas, HCCI - Homogeneous Charge Compression Ignition, HPDI - High Pressure Direct Injection, IVO Inlet valve opening, LPG - Liquefied Petroleum Gas, MA - Metlyuk-Avtushko, RCCI - Reactivity Controlled Compression Ignition, RDE - Real Driving Emissions, SVW - St'Venant and Wantzel, TDC - Top Dead Centre, WLTP - World Harmonized Light Vehicle Test Procedure.

Glossary: $\mathrm{a}$ - acceleration, $\mathrm{A}_{\mathrm{p}}$ - piston area, $\mathrm{b}$ - constant parameter value of $\mathrm{MA}$ flow function, $\mathrm{F}_{\mathrm{c}}$ - force acting in the connecting rod axis, $\mathrm{F}_{\mathrm{g}}$ - gas force acting on the piston, $\mathrm{F}_{\text {net }}-\mathrm{re}$ sistance force of mass inertia in reciprocating motion, $F_{t}$ - the force tangent to the crank radius, $\dot{V}$ - rate of change in volume, $\mathrm{V}_{\mathrm{c}}$ - volume of cylinder, $\mathrm{m}_{\mathrm{A}}$ - weight of the components involved in the reciprocal motion, $m_{B}$ - the substitute mass of the part of the connecting rod rotating on radius $\mathrm{R}$ of the $\mathrm{x}$-th crank, $\mathrm{L}$ - the length of the connecting rod, $\mathrm{p}$ - pressure, $\mathrm{R}$ - the crank radius, $\mathrm{R}_{\mathrm{g}}$ - gas constant, $\mathrm{T}_{\mathrm{g}}$ - air temperature, $\mathrm{V}$ - volume, $\mathrm{x}$ - displacement of pistons.

Greek symbols: $\alpha$ - the angle of crankshaft rotation, $\kappa-$ adiabatic exponent, $\lambda$ - the connecting rod coefficient, $(\mu \mathrm{A})-$ throughput, $\sigma$-pressure ratio, $\psi(\sigma)$ - dimensionless function of flow.

Indexes: c - closing, $\mathrm{f}$ - full, inlet, in - inlet, max - maximum volume, o- opening, outlet, out - outlet.

\section{APPENDIX}

\section{A1. MECHANICAL SUBSYTEM}

The displacement of the piston without taking in account displacement of the cylinder axis related to the crankshaft axis was presented in the form (Szpica, 2018a):

$x=R\left[(1-\cos \alpha)+\frac{\lambda}{4}(1-\cos 2 \alpha)\right]$

where: $\lambda=L \backslash R$. tion:

The movement of the piston was described by vector equa-

$\vec{F}_{g}+\vec{F}_{c}+\vec{N}=m_{A} \vec{a}$

where: $\quad \vec{F}_{g}=p_{c}(\alpha) A_{p} \mathbf{i}, \quad \vec{F}_{c}=\frac{F_{g}-F_{n e t}}{\cos \beta} \mathbf{l}, \quad \vec{F}_{n e t}=-m_{A} \ddot{x}$, $a=\ddot{x}=\frac{\mathrm{D} \dot{V}_{c}}{A_{p}}$, $\mathbf{i}$ and $\mathbf{l}-$ see Fig. 2 .

Engine torque is described:

$\vec{T}_{r}=\vec{R} \times \vec{F}_{t}=(\mathbf{r} \times \mathbf{t})\left(F_{g}+F_{n e t}\right) \frac{R \sin (\alpha+\beta)}{\cos \beta}$

Because $\mathbf{r} \times \mathbf{t}=-\mathbf{k}$ :

$\vec{T}_{r}=-R\left(F_{g}+F_{n e t}\right) \frac{\sin (\alpha+\beta)}{\cos \beta} \mathbf{k}$

where: $\mathbf{k}$ - see Fig. 2.

$T_{r}=\frac{R A_{p} \sin (\alpha+\beta)}{\cos \beta} p_{c}(\alpha)-\frac{R m_{A} \sin (\alpha+\beta)}{A_{p} \cos \beta} \dot{V}_{c}(\alpha)$

\section{A2. PNEUMATIC SUBSYSTEM}

Having considered the above assumptions, the stream of air flowing through the local drag was expressed as (Fig. 2) (Kaminski, 2013, Kaminski 2014, Szpica, 2018b):

$\dot{m}=\frac{\mathrm{d} m}{\mathrm{~d} t}=(\mu A) \frac{p}{\sqrt{R T_{g}}} \psi_{\max } \psi(\sigma)$

The air pressure change in the lumped elements with a variable volume $V$ was described:

$\frac{\mathrm{d} p}{\mathrm{~d} t}=\frac{\kappa R_{g} T_{g}}{V}\left(\dot{m}-\frac{p}{R_{g} T_{g}} \frac{\mathrm{d} V}{\mathrm{~d} t}\right)$

The dimensionless two-range $S V W$ flow function was inconvenient during the modelling, hence the single-range $M A$ hyperbolic function (Szpica, 2018c) $\psi(\sigma) b \frac{1-\sigma}{b-\sigma}$, where $\sigma=p_{\text {in }} / p_{\text {out }}$.

\section{REFERENCES}

1. A policy framework for climate and energy in the period from 2020 to 2030. 2014. Communication From The Commission To The European Parliament, The Council, The European Economic And Social Committee And The Committee Of The Regions.

2. Allam S., Zakaria M. (2018), Experimental investigation of compressed air engine performance, International Journal of Engineering Inventions, 7(1), 13-20.

3. Badr O., Probert S.D., O'Callaghan P.W. (1985), Multi-vane expanders: internal-leakage losses, Applied Energy, 20(1), 1-46.

4. Borawski A. (2015), Modification of a fourth generation LPG installation improving the power supply to a spark ignition engine, Eksploatacja i Niezawodnosc - Maintenance and Reliability, 17(1), 1-6. 
5. Borawski A. (2016), Suggested research method for testing selected tribological properties of friction components in vehicle braking systems, Acta Mechanica et Automatica, 10(3), 223-226.

6. Borawski A. (2019), Common methods in analysing the tribological properties of brake pads and discs - a review, Acta Mechanica et Automatica, 13(3), 189-199.

7. Brejaud P., Higelin P., Charlet A. et al. (2011), Convective Heat Transfer in a Pneumatic Hybrid Engine, Oil \& Gas Science and Technology, 66(6), 1035-1051.

8. Commission Regulation (EU) 2017/1154 of 7 June 2017 amending Regulation (EU) 2017/1151 supplementing Regulation (EC) No 715/2007 of the European Parliament and of the Council on typeapproval of motor vehicles with respect to emissions from light passenger and commercial vehicles (Euro 5 and Euro 6) and on access to vehicle repair and maintenance information, amending Directive 2007/46/EC of the European Parliament and of the Council, Commission Regulation (EC) No 692/2008 and Commission Regulation (EU) No 1230/2012 and repealing Regulation (EC) No 692/2008 and Directive 2007/46/EC of the European Parliament and of the Council as regards real-driving emissions from light passenger and commercial vehicles (Euro 6), Official Journal of the European Union, L175, 7.7.2017, page 708.

9. Czarnigowski J. (2012), Teoretyczno-empiryczne studium modelowania impulsowego wtryskiwacza gazu, Politechnika Lubelska, Lublin.

10. Dimitrova Z., Marechal F. (2015), Gasoline hybrid pneumatic engine for efficient vehicle powertrain hybridization, Applied Energy, 151, 168-177.

11. Duk M., Czarnigowski J. (2012), The method for indirect identification gas injector opening delay time, Przeglad Elektrotechniczny, 88(10b), 59-63.

12. Dvorak L., Fojtasek K., Rehacek V. (2017), Calculations of parameters and mathematical model of rotary air motor, EPJ Web of Conferences, 143, 02018, 4p.

13. Fang Y.D., Lu Y.J., Yu X.L., Roskilly A.P. (2018), Experimental study of a pneumatic engine with heat supply to improve the overall performance, Applied Thermal Engineering, 134, 78-85.

14. Fox J.T., Yang K., Hunsicker R. (2019), Diesel Particulate Filter Cleaning Effectiveness: Estimated Ash Loading, Quantified Particulate Removal, and Post-cleaning Filter Pressure Drop. Emission Control Science and Technology, 1-11 (on-line).

15. Grigor'ev M.A., Naumovich N.I., Belousov E.V. (2015), A traction electric drive for electric cars, Russian Electrical Engineering, 86(12), 731-734

16. Heywood B.H. (1988), Internal combustion engine fundamentals, McGraw-Hill Series in Mechanical Engineering, New York, USA.

17. http://wltpfacts.eu/ [online cit.: 2019.11.10].

18. http://www.engineair.com.au/ [online cit.: 2019.11.10]

19. http://www.jawa-50.cz/clanek/jawa-23-mustang-technicke-udaje.html [online cit:: 2019.11.10].

20. https://www.mdi.lu/ [online cit.: 2019-03.01]

21. Jeuland N., Montagne X., Duret P. (2004), New HCCl/CAl combustion process development: Methodology for determination of relevant fuel parameters, Oil \& Gas Science and Technology, 59(6),571-579.

22. Kalekin V.S., Kalekin D.V., A. N. Nefedchenko A.N. (2014), A Mathematical Model of a Piston Pneumatic Engine with Self-Acting air Distribution, Chemical and Petroleum Engineering, 50(1-2), 9198.

23. Kaminski Z. (2013), Experimental and numerical studies of mechanical subsystem for simulation of agricultural trailer air braking systems, International Journal of Heavy Vehicle System, 20(4), 289311.

24. Kaminski Z. (2014), Mathematical modelling of the trailer brake control valve for simulation of the air brake system of farm tractors equipped with hydraulically actuated brakes, Eksploatacja Niezawodnosc - Maintenance and Reliability, 16(4), 637-643.
25. Librovich B.V., Nowakowski A.F. (2004), Analysis, design, and modeling of a rotary vane engine (RVE), Journal of Mechanical Design, 126(4), 711-720.

26. Michael M., Voser C., Onder C et al. (2012), Design methodology of camshaft driven charge valves for pneumatic engine starts, IFAC Proceedings, 45(30), 33-40.

27. Mieczkowski G. (2017), The constituent equations of piezoelectric cantilevered three-layer actuators with various external loads and geometry, Journal of Theoretical and Applied Mechanics, 55(1), 6986

28. Mieczkowski G. (2018), Optimization and prediction of durability and utility features of three-layer piezoelectric transducers, Mechanika, 24(3), 335-342.

29. Mieczkowski G. (2019), Criterion for crack initiation from notch located at the interface of bi-material structure, Eksploatacja Niezawodnosc - Maintenance and Reliability, 21(2), 301-310.

30. Mieczkowski G., Borawski A., Szpica D. (2020), Static electromechanical characteristic of a three-layer circular piezoelectric transducer, Sensors, 20, 222, 14p.

31. Mikulski M., Balakrishnan P.R., Doosje E. et al. (2018), Variable Valve Actuation Strategies for Better Efficiency Load Range and Thermal Management in an RCCI Engine, SAE Technical Papers, 2018-01-0254, 14p

32. Mikulski M., Wierzbicki S., Pietak A. (2015), Numerical studies on controlling gaseous fuel combustion by managing the combustion process of diesel pilot dose in a dual-fuel engine, Chemical and Process Engineering - Inzynieria Chemiczna i Procesowa, 36 (2), 225-238.

33. Mitianiec W. (2008), Pneumatic two-stroke engine as an alternative power source, Journal of KONES Powertrain and Transport, 15(3), 357-366.

34. Onishi S., Hong J.S., Do J.S. et al. (1979), Active thermoatmosphere combustion (A.T.A.C.) - A new combustion process for internal combustion engines, SAE Paper 790501

35. Pulawski G., Szpica D. (2015), The modelling of operation of the compression ignition engine powered with diesel fuel with LPG admixture, Mechanika, 21(6), 501-506;

36. Raslavicius L., Kersys A. Makaras R. (2017), Management of hybrid powertrain dynamics and energy consumption for 2WD, 4WD, and HMMWV vehicles, Renewable and Sustainable Energy Reviews, 68(1), 380-396.

37. Raslavicius L., Kersys A., Mockus S. et al. (2014), Liquefied petroleum gas (LPG) as a medium-term option in the transition to sustainable fuels and transport, Renewable \& Sustainable Energy Reviews, 32, 513-525.

38. Resitoglu I.A., Altinisik K., Keskin A. et al. (2020), The effects of $\mathrm{Fe} 2 \mathrm{O} 3$ based DOC and SCR catalyst on the exhaust emissions of diesel engines, Fuel, 262, 116501.

39. Semenchukova V., Grishin Y., Malastowski N. (2018), Mathematical modeling of a piston engine pneumatic start, International Russian Automation Conference (RusAutoCon), 1-4.

40. Senthil Kumar J., Ramesh Bapu B.R., Sivasaravanan S. et al. (2019), Experimental studies on emission reduction in DI Diese engine by using nano catalyst coated catalytic converter, International Journal of Ambient Energy, 1-17 (on-line).

41. Simon M. (2017), Pneumatic vehicle, research and design, Procedia Engineering, 181, 200-205.

42. Szpica D. (2016), The influence of selected adjustment parameters on the operation of LPG vapor phase pulse injectors, Journal of Natural Gas Science and Engineering, 34, 1127-1136.

43. Szpica D. (2018a), Modelling of the operation of a Dual Mass Flywheel (DMF) for different engine-related distortions, Mathematical and Computer Modelling of Dynamical Systems, 24(6), 643-660.

44. Szpica D. (2018b), Research on the influence of LPG/CNG injector outlet nozzle diameter on uneven fuel dosage, Transport, 33(1), 186196.

45. Szpica D. (2018c), The determination of the flow characteristics of a low-pressure vapor-phase injector with a dynamic method, Flow Measurement and Instrumentation, 62, 44-55. 
46. Walus K.J., Wargula L., Krawiec P. et al. (2018), Legal regulations of restrictions of air pollution made by non-road mobile machinery - the case study for Europe: a review, Environmental Science and Pollution Research, 25(4), 3243-3259.

47. Wargula L., Walus K. J., Krawiec P. (2018), Small engines spark ignited (SI) for non-road mobile machinery-review, Proceedings of 22 Ind International Scientific Conference. Transport Means 2018, T.2, 585-591.
48. Zwierzchowski J. (2017), Design type air engine Di Pietro, EPJ Web Conf., 14302149.

The research has been carried out within work no. S/WM/1/18 realized at Bialystok University of Technology and financed from the funding allocated for science by the Ministry of Science and Higher Education, Poland. 